\title{
The dynamics of epidural and opioid analgesia during labour
}

\author{
Dirkje C. Zondag ${ }^{1} \cdot$ Mechthild M. Gross $^{1} \cdot$ Susanne Grylka-Baeschlin $^{1} \cdot$ \\ Angela Poat $^{2} \cdot$ Antje Petersen $^{1}$
}

Received: 10 December 2015/ Accepted: 26 April 2016/Published online: 19 May 2016

(C) Springer-Verlag Berlin Heidelberg 2016

\begin{abstract}
Purpose To investigate the association of analgesia, opioids or epidural, or the combination of both with labour duration and spontaneous birth in nulliparous women.

Methods A secondary data analysis of an existing cohort study was performed and included nulliparous women $(n=2074)$. Durations of total labour and first and second labour stage were calculated with Kaplan-Meier estimation for the four different study groups: no analgesia $(n=620)$, opioid analgesia $(n=743)$, epidural analgesia $(n=482)$, and combined application $(n=229)$. Labour duration was compared by Cox regression while adjusting for confounders and censoring for operative births. Logistic regression was used to investigate the association between the administration of different types of analgesia and mode of birth.

Results Most women in the combined application group were first to receive opioid analgesia. Women with no analgesia had the shortest duration of labour (log rank $p<0.001)$ and highest chance of a spontaneous birth $(p<0.001)$. If analgesia was administered, women with opioids had a shorter first stage $(p=0.018)$, compared to women with epidural $(p<0.001)$ or women with combined application $(p<0.001)$. Women with opioids had an increased chance to reach full cervical dilatation
\end{abstract}

This study based on the M.Sc. thesis of the first author. The data set was funded by the German Research Council (DFG).

Antje Petersen

Petersen.Antje@mh-hannover.de

1 Midwifery Research and Education Unit, Hannover Medical School, Carl-Neuberg-Str. 1, 30625 Hannover, Germany

2 Faculty of Health and Social Care, University of Hull, Hull HU6 7RX, UK $(p=0.006)$. Women with epidural analgesia $(p<0.001)$ and women with combined application $(p<0.001)$ had a prolonged second stage and decreased chance of spontaneous birth compared to women without analgesia.

Conclusions Women with opioids had a prolonged first stage, but increased chance to reach full cervical dilatation. Women with epidural analgesia and women with both opioid and epidural analgesia had a prolonged first and second stage and a decreased chance of a spontaneous birth.

Keywords Combined analgesia - Labour duration . Spontaneous birth · Cox regression · Longitudinal studies . Timing of interventions

$\begin{array}{ll}\begin{array}{l}\text { Abbreviations } \\ \text { ACOG }\end{array} & \begin{array}{l}\text { American Congress of Obstetrics and } \\ \text { Gynecologists }\end{array} \\ \text { EDD } & \text { Expected delivery date } \\ \text { HR } & \text { Hazard ratio } \\ \text { CI } & \text { Confidence interval } \\ \text { PROM } & \text { Prelabour rupture of membranes } \\ \text { VBAC } & \text { Vaginal birth after caesarean }\end{array}$

\section{Introduction}

In recent years, more childbearing women opt for pain relief during labour [1, 2]. Women's pain perception in labour is affected by physiological and psychosocial factors $[3,4]$. Variables that are suggested to influence the experience of labour pain are prior experience of labour and childbirth, culture and ethnicity, educational attainment, and women's ability to cope $[4,5]$. 
Midwives have an important role in the attempt to break the cycle of fear-tension-pain through the education of pregnant women, regarding labour pain and emotional support during labour [4, 6, 7]. Different interventions can change women's experiences of pain and can be focused on pain sensation or pain perception $[5,8,9]$. Continuous support in labour appears to shorten labour, decrease the risk of intrapartum analgesia or dissatisfaction with childbirth experience and increase the chance of a spontaneous birth $[10,11]$. In addition, women who received midwifeled continuity of care are less likely to use pharmacological pain relief, have fewer interventions, and have an increased sense of control [12, 13]. Pain perception can also be affected by stimulating mobility and trying different positions as well as by non-pharmacological interventions like immersion, relaxation, and acupuncture $[1,14-16]$.

The decision on whether or not to administer pharmacological analgesia should be based on informed choice, because pharmacological pain relief methods may impact on labour progress $[1,17,18]$. Variety regarding the amount of intrapartum pharmacological pain relief worldwide is caused by differing women's attitudes, caregivers' views, and availability $[10,17,19,20]$. Intrapartum epidural analgesia and opioid administration are established pain relief methods. Epidural analgesia is the most effective type of analgesia and has the highest rate of maternal satisfaction in regard to pain relief $[1,19]$. However, epidural analgesia is associated with a prolonged second stage of labour and increased risk of instrumental births $[1,19]$. Furthermore, women need to be informed about the other side effects like blood pressure disturbances, difficulties with micturition, and the risk of nerve damage, infections, and haematomas [1, 19]. Alternatively, opioid analgesia is often administrated because of the relatively low costs and easy administration [20], although there is an insufficient evidence for its effectiveness during labour available [1]. There also remains a debate on whether opioid analgesia is associated with the length of the active phase of labour [14, 19]. General known side effects of opioid analgesia, besides nausea and vomiting, are drowsiness, blood pressure disturbances, and passive placenta diffusion which can cause neonatal respiratory depression $[1,14,20]$. No study has been found which analysed the combination of epidural and opioid analgesia during labour with respect to sequence and timing.

Information on duration of labour in relation to the type of analgesia could protect women from an unjustified diagnosis of dystocia. Therefore, this longitudinal study aimed to investigate if and how opioid analgesia, epidural analgesia, or the combination of both are associated with (a) the duration of first and second stage of labour and (b) giving birth spontaneously.

\section{Methods}

This study was designed as a secondary data analysis of the ProGeb-study [21]. The ProGeb-study was a longitudinal cohort study and investigated multiple associations of obstetric interventions on the process of labour among lowrisk women [22]. Data were documented either prospectively during labour by the attending midwife $(n=1169)$ or retrospectively $(n=2786)$ extracted from medical records and the state-wide perinatal auditing database at the Centre for Quality and Management in Health Care, Lower Saxony Chamber of Physicians. The same documentation form was used for prospective and retrospective data before digitalisation. Women giving birth in one of the 47 participating maternity units in Germany were included in the cases of a low-risk pregnancy of a singleton with a cephalic presentation, at least 34 week gestation and a planned vaginal birth. Onset of labour was defined as regular or irregular contractions, in association with cervical dilatation [23].

Written informed consent was obtained from women in the prospective sample before inclusion in the study. Institutional approval for the anonymous gathering of information was granted by the Ethics Committee of Hannover Medical School and by the Ethics Committee of the Chamber of Physicians for all public hospitals in Lower Saxony.

The study was designed to detect a hazard ratio of 1.2 at the level alpha (two-sided) 0.05 with a power of $80 \%$, whereby the necessary sample size was calculated at $n=980$. The ProGeb-study included data of 2090 nulliparae and 1873 multiparae. For this study, only the nulliparae without prelabour epidural $(n=16)$ were included. Inclusion of pregnancies of $\geq 34$ weeks of gestation was decided because of a German guideline which recommends care for these as normal births [24]. Women with a previous caesarean section, but no previous vaginal birth and induced labours were included in the study following earlier ProGeb-studies [21].

The study sample was divided into four study groups: (1) women without analgesia $(n=620,29.9 \%)$, (2) women with only opioid analgesia $(n=743,35.8 \%)$, (3) women with only epidural analgesia $(n=482,23.2 \%)$, and (4) women with opioid and epidural analgesia $(n=229,11.0 \%)$. In the total study sample $(\mathrm{n}=2074)$, 711 women $(34.3 \%)$ had an epidural analgesia (bolus, combined spinal-epidural, or patient controlled) during labour and 977 women $(47.1 \%)$ had an intrapartum opioid analgesia. Application schemes differed widely between units [25]. Three types of opioid analgesia were taken together in this group namely Pethidine, Meptazinol, and Pentazocin. In the study, group 2 and 4 opioids were 
administered intravenously or intramuscularly. It is likely that epidural opioids have been administered in group 3 and 4 , but this was not recorded.

The statistical programmes SPSS (version 22) and Stata (version 13) were used for the analysis. Baseline characteristics for each study group were computed with descriptive statistics, and the significance of the differences between the study groups were calculated with the use of the Chi-square, ANOVA, and Kruskal-Wallis tests. Kaplan-Meier survival curves were used to analyse labour duration of the first and second stage, and these were compared with the log-rank test. Operative births were treated as censored data meaning that participants did not reach the end point spontaneous birth [26]. To investigate which factors were associated with the application of opioid analgesia, epidural analgesia, or the combination of both types of analgesia, a multinominal logistic regression was performed.

Thereafter, logistic regression was applied to assess the chance of full cervical dilatation and spontaneous birth. Durations of the first and second stage were compared by Cox regression while adjusting for confounding time constant factors and censoring for operative births. For the multivariable models analysing spontaneous birth and duration of first and second stage, variables were included in the first step of the regression if their significance level was $<0.25$ in the bivariable test according to the modelbuilding strategies of Hosmer and Lemeshow [27]. The factors maternal age, risks before onset of labour, VBAC, PROM, cervical dilatation at admission, induction, oxytocin augmentation, fetal weight, and a variable on type of data recording were included in all multivariable models. In addition, the factors obesity and sex of the baby were entered in the models for the duration of the second stage of labour and chance on a spontaneous birth, because they had a significance level of $p<0.25$ in the bivariate test for the second stage of labour. In the logistic regression chance of a spontaneous birth, the factor total duration of labour was also entered.

Variables were backward eliminated in descending order, until only variables remained in the model with a significance level of 0.05 or lower. Maternal age, fetal weight, and type of data (prospective or retrospective) remained in the multivariable model regardless of the significance of the association with the dependent variable.

The Cox regression model estimated variables regarding a dependent process, for example, length of first stage, length of second stage and provided a hazard ratio (HR), and an associated $95 \%$ confidence interval with $p$ value. A hazard ratio that was smaller than 1 in a sample with censored events was interpreted as later, whereas a hazard ratio greater than 1 was interpreted as earlier.

\section{Findings}

\section{Baseline characteristics}

Women without any analgesia had the highest proportion of being without any risk before the onset of labour $(p=0.003$, Table 1). Obesity was most often a risk factor in women with epidural analgesia $(n=20,4.1 \%)$ or a combination of both analgesia types $(n=19,8.3 \%)$. When examining the perinatal factors, women who did not receive any analgesia were admitted to labour ward with median $3 \mathrm{~cm}$ cervical dilatation, whereas all women who received analgesia were admitted earlier $(2 \mathrm{~cm}$, $p<0.001)$. Women who were induced or received oxytocin augmentation received more frequently an epidural analgesia or a combination of opioids and epidural analgesia $(p<0.001)$.

\section{Description of labour analgesia}

When only epidural analgesia was administered, women received an epidural significantly earlier $(\mathrm{md}=3.68 \mathrm{~h}$, range $0.00-51.17 \mathrm{~h}$ ) compared to the group with an epidural as well as opioids $(\mathrm{md}=6.67 \mathrm{~h}$, range $1.00-48.64 \mathrm{~h}, p<0.001)$. Women in the fourth study group most often received an opioid first $(n=224$, $97.8 \%$ ). The median difference between opioid and epidural analgesia was $2.65 \mathrm{~h}$ (range $0.17-17.50 \mathrm{~h}$ ). Five women $(2.2 \%)$ received an epidural first and then opioid analgesia in median $7.67 \mathrm{~h}$ (range 3.58-12.25 h) after the onset of labour.

Only a few women needed additional analgesia if epidural analgesia was administered first. Furthermore, 982 $(47.3 \%)$ women received a different type of pharmacological analgesia, such as Butylscopolaminiumbromid (Buscopan $\odot$ ). Analyses showed that if opioids $(n=494$, $66.5 \%)$ or opioids and epidural analgesia $(n=153$, $66.8 \%$ ) were administered, women were more likely to receive additional analgesia.

\section{Administration of labour analgesia}

According to factors associated with the administration of labour analgesia, it appeared that women of 35 years or older $(p=0.031)$, who had less than $3 \mathrm{~cm}$ cervical dilatation at admission $(p<0.001)$ or had oxytocin augmentation $(p=0.002)$, were more likely to receive opioid analgesia (Table 2). Women with prelabour rupture of membranes (PROM) $(p=0.038)$, induction $(p<0.001)$, or oxytocin augmentation $(p<0.001)$ were more likely to be administered epidural analgesia. Likewise, women with less than $3 \mathrm{~cm}$ cervical dilatation at admission $(p<0.001)$, 
Table 1 Baseline characteristics of the 2074 nulliparae (including VBAC) by study group

\begin{tabular}{|c|c|c|c|c|c|}
\hline Characteristic & $\begin{array}{l}\text { 1: no opioids or epidural } \\
(n=620)\end{array}$ & $\begin{array}{l}\text { 2: only opioids } \\
(n=743)\end{array}$ & $\begin{array}{l}\text { 3: only epidural } \\
(n=482)\end{array}$ & $\begin{array}{l}\text { 4: opioids and epidural } \\
(n=229)\end{array}$ & $p$ value $^{\mathrm{B}}$ \\
\hline \multicolumn{6}{|l|}{ Social-demographic } \\
\hline \multicolumn{6}{|l|}{ Maternal age in years } \\
\hline Mean (min-max) & $28.8(16-45)$ & $27.7(14-46)$ & $28.8(15-45)$ & $28.1(15-44)$ & \\
\hline SD & 5.45 & 5.63 & 5.53 & 5.83 & 0.439 \\
\hline Private health insurance ${ }^{\mathrm{A}}$ & $52(8.4)$ & $46(6.2)$ & $48(10.0)$ & $14(6.1)$ & 0.070 \\
\hline \multicolumn{6}{|l|}{ Obstetrical history } \\
\hline No risks before the onset of labour ${ }^{\mathrm{A}}$ & $372(60.0)$ & $410(55.2)$ & $272(56.4)$ & $105(45.9)$ & 0.003 \\
\hline $\mathrm{VBAC}^{\mathrm{A}}$ & $72(11.6)$ & $63(8.5)$ & $50(10.4)$ & $24(10.5)$ & 0.284 \\
\hline Obesity $^{\mathrm{A}}$ & $20(3.2)$ & $24(3.2)$ & $20(4.1)$ & $19(8.3)$ & 0.004 \\
\hline Diabetes Mellitus ${ }^{\mathrm{A}}$ & $5(0.8)$ & $2(0.3)$ & $4(0.8)$ & $2(0.9)$ & 0.496 \\
\hline Gestational diabetes $^{\mathrm{A}}$ & $24(3.9)$ & $19(2.6)$ & $18(3.7)$ & $8(3.5)$ & 0.530 \\
\hline $\begin{array}{l}\text { Difference from EDD in days } \\
\text { (median, } \mathrm{min} / \mathrm{max})\end{array}$ & $-1(-41 / 19)$ & $0(-41 / 16)$ & $1(-42 / 18)$ & $1(-40 / 16)$ & 0.002 \\
\hline $\mathrm{PROM}^{\mathrm{A}}$ & $139(22.4)$ & $172(23.1)$ & $145(30.1)$ & $66(28.8)$ & 0.008 \\
\hline \multicolumn{6}{|l|}{ Perinatal factors } \\
\hline $\begin{array}{l}\text { Cervical dilatation at admission } \\
\text { (median, } \min / \max )\end{array}$ & $3.00(0.00 / 10.00)$ & $2.00(0.00 / 10.00)$ & $2.00(0.00 / 10.00)$ & $2.00(0.00 / 9.00)$ & $<0.001$ \\
\hline Induction $^{\mathrm{A}}$ & $144(23.2)$ & $194(26.1)$ & $179(37.1)$ & $82(35.8)$ & $<0.001$ \\
\hline Oxytocin augmentation $^{\mathrm{A}}$ & $203(32.7)$ & $349(47.0)$ & $345(71.6)$ & $190(83.0)$ & $<0.001$ \\
\hline $\begin{array}{l}\text { Additional analgesia } \\
\text { (Buscopan } \odot)^{\mathrm{A}}\end{array}$ & $178(28.7)$ & $494(66.5)$ & $157(32.7)$ & $153(66.8)$ & $<0.001$ \\
\hline \multicolumn{6}{|l|}{ Modus partus ${ }^{\mathrm{A}}$} \\
\hline Spontaneous & $489(78.87)$ & $592(79.68)$ & $285(59.13)$ & $119(51.97)$ & $<0.001$ \\
\hline Instrumental & $33(5.32)$ & $67(9.02)$ & $76(15.77)$ & $39(17.03)$ & $<0.001$ \\
\hline Caesarean section & $98(15.81)$ & $84(11.30)$ & $121(25.10)$ & $71(31.00)$ & $<0.001$ \\
\hline Fetal birth weight in gram & 3360.69 & 3427.54 & 3422.50 & 3469.66 & \\
\hline Mean (min-max) & $(1720-5070)$ & $(1970-4730)$ & $(2070-5370)$ & $(2220-4770)$ & \\
\hline SD & 4.89 & 4.64 & 4.78 & 4.46 & 0.460 \\
\hline $\begin{array}{l}\text { Sex of the baby }{ }^{\mathrm{A}} \text { (proportion } \\
\text { females) }\end{array}$ & $310(50.0)$ & $364(49.0)$ & $234(48.6)$ & $107(46.7)$ & 0.863 \\
\hline \multicolumn{6}{|l|}{ Data information } \\
\hline Retrospective data ${ }^{\mathrm{A}}$ & $429(69.2)$ & $524(70.5)$ & $382(79.3)$ & $132(57.6)$ & $<0.001$ \\
\hline \multicolumn{6}{|l|}{ Duration of labour in vaginal births } \\
\hline $\begin{array}{l}\text { First stage in hours-md } \\
(\min / \max )^{\mathrm{C}}\end{array}$ & $5.32(0.00 / 55.50)$ & $6.92(0.92 / 75.33)$ & $7.87(0.83 / 52.25)$ & $10.50(2.08 / 51.88)$ & \\
\hline $\begin{array}{l}\text { Second stage in hours-md } \\
(\min / \max )^{\mathrm{D}}\end{array}$ & $0.60^{*}(0.00 / 4.50)$ & $0.58(0.00 / 8.07)$ & $1.33^{¥}(0.00 / 5.05)$ & $1.30(0.21 / 4.50)$ & \\
\hline
\end{tabular}

A Number of women and percentage $[n,(\%)]$

B Calculated with the Chi-square test, ANOVA, or Kruskal-Wallis test. ANOVA was used for maternal age and fetal weight, the Kruskal-Wallis test was used for the difference in EDD and cervical dilatation at admission

C $n=294$ censored due to caesarean section during the first stage of labour

D $n=295$ censored due to operative vaginal delivery or caesarean section

* Not statistically significant different with study group 2

$¥$ Not statistical significant different with study group 4

an induction $(p=0.012)$, oxytocin augmentation $(p<0.001)$, or who were included in the retrospective data set $(p=0.007)$ had more chance on the administration of the combination of opioid and epidural analgesia. Each additional hour of labour increased the risk of administration of both types of analgesia by $9.3 \%$, the risk increased by $4.9 \%$ for opioid administration and by $5.8 \%$ for administration of epidural analgesia. 
Table 2 Multinominal logistic regression: association of factors from administration of opioid analgesia, epidural analgesia, or combination of both during labour compared to those without analgesia $(n=2074)$

\begin{tabular}{|c|c|c|c|}
\hline Variable & OR & $95 \% \mathrm{CI}$ & $p$ value \\
\hline \multicolumn{4}{|l|}{ Opioid analgesia } \\
\hline Maternal age ( $\geq 35$ years) & 1.434 & $1.034-1.988$ & 0.031 \\
\hline Private insurance & 0.785 & $0.511-1.205$ & 0.268 \\
\hline VBAC & 0.691 & $0.475-1.007$ & 0.054 \\
\hline Obesity & 0.864 & $0.460-1.624$ & 0.650 \\
\hline Difference in EDD & 1.007 & 0.996-1.019 & 0.198 \\
\hline PROM & 0.980 & $0.741-1.296$ & 0.887 \\
\hline Cervical dilatation at admission ${ }^{\mathrm{a}}$ & 0.404 & $0.319-0.510$ & $<0.001$ \\
\hline Induction & 1.042 & $0.795-1.364$ & 0.767 \\
\hline Oxytocin augmentation & 1.450 & $1.143-1.841$ & 0.002 \\
\hline Fetal weight $(\geq 4000 \mathrm{~g})$ & 1.402 & $0.965-2.037$ & 0.076 \\
\hline Sex of the baby & 0.930 & $0.743-1.163$ & 0.522 \\
\hline Labour duration & 1.049 & $1.024-1.074$ & $<0.001$ \\
\hline Retrospective data & 1.087 & $0.849-1.385$ & 0.515 \\
\hline \multicolumn{4}{|l|}{ Epidural analgesia } \\
\hline Maternal age ( $\geq 35$ years) & 1.206 & $0.846-1.718$ & 0.301 \\
\hline Private insurance & 1.256 & $0.806-1.959$ & 0.314 \\
\hline VBAC & 1.012 & $0.668-1.533$ & 0.955 \\
\hline Obesity & 0.957 & $0.487-1.880$ & 0.898 \\
\hline Difference in EDD & 1.008 & $0.995-1.022$ & 0.210 \\
\hline PROM & 1.386 & $1.018-1.887$ & 0.038 \\
\hline Cervical dilatation at admission ${ }^{\mathrm{a}}$ & 0.823 & $0.631-1.074$ & 0.152 \\
\hline Induction & 1.871 & $1.394-2.513$ & $<0.001$ \\
\hline Oxytocin augmentation & 4.338 & $3.295-5.710$ & $<0.001$ \\
\hline Fetal weight $(\geq 4000 \mathrm{~g})$ & 0.874 & $0.559-1.367$ & 0.556 \\
\hline Sex of the baby & 0.907 & $0.702-1.173$ & 0.458 \\
\hline Labour duration & 1.058 & $1.032-1.085$ & $<0.001$ \\
\hline Retrospective data & 1.752 & $1.299-2.362$ & $<0.001$ \\
\hline \multicolumn{4}{|l|}{ Opioid and epidural analgesia } \\
\hline Maternal age ( $\geq 35$ years) & 1.221 & $0.764-1.950$ & 0.404 \\
\hline Private insurance & 0.797 & $0.412-1.543$ & 0.501 \\
\hline VBAC & 1.021 & $0.591-1.764$ & 0.939 \\
\hline Obesity & 1.439 & $0.699-2.963$ & 0.324 \\
\hline Difference in EDD & 1.012 & $0.994-1.030$ & 0.202 \\
\hline PROM & 1.366 & $0.919-2.030$ & 0.123 \\
\hline Cervical dilatation at admission ${ }^{\mathrm{a}}$ & 0.284 & $0.193-0.418$ & $<0.001$ \\
\hline Induction & 1.622 & $1.113-2.362$ & 0.012 \\
\hline Oxytocin augmentation & 6.612 & 4.414-9.905 & $<0.001$ \\
\hline Fetal weight $(\geq 4000 \mathrm{~g})$ & 1.090 & $0.637-1.867$ & 0.752 \\
\hline Sex of the baby & 0.802 & $0.573-1.122$ & 0.198 \\
\hline Labour duration & 1.093 & $1.064-1.123$ & $<0.001$ \\
\hline Retrospective data & 0.617 & $0.435-0.876$ & 0.007 \\
\hline
\end{tabular}

${ }^{a}$ Cervical dilatation is divided in less than $3-\mathrm{cm}$ dilatation (= reference) and $3 \mathrm{~cm}$ or more

\section{Duration of first and second stage}

Women without analgesia had significantly shorter durations of first stage of labour compared to the groups with analgesia $(\mathrm{md}=5.3 \mathrm{~h}$, Table 1 ; Fig. 1). Women with opioids and epidural had the longest duration compared to the other study groups $(\mathrm{md}=10.5 \mathrm{~h}, p<0.001)$. For women with opioids, the median duration of the first stage of labour was $6.9 \mathrm{~h}$ which was significantly longer than women without analgesia $(p<0.001)$ and significantly shorter than women with epidural ( $\mathrm{md}=7.9 \mathrm{~h}, p=0.010$ ) and women with opioids and epidural $(p<0.001)$.

The median duration of the second stage of labour (Table 1; Fig. 2) for the group with epidural analgesia was $78.0 \mathrm{~min}$ and did not differ from $79.8 \mathrm{~min}$ for combined application. The median duration for the groups with opioids $(35.0 \mathrm{~min})$ or without analgesia $(36.0 \mathrm{~min})$ were significantly shorter $(p<0.001)$ but did not differ significantly from each other $(p=0.673)$.

In the multivariable Cox regression, the first stage of labour was significantly prolonged for the groups with analgesia compared to women without analgesia (Table 3). Duration of the first stage was the most prolonged for women with both opioids and epidural (HR 0.521, $95 \%$ CI $0.434-0.624, p<0.001$ ), followed by women with an

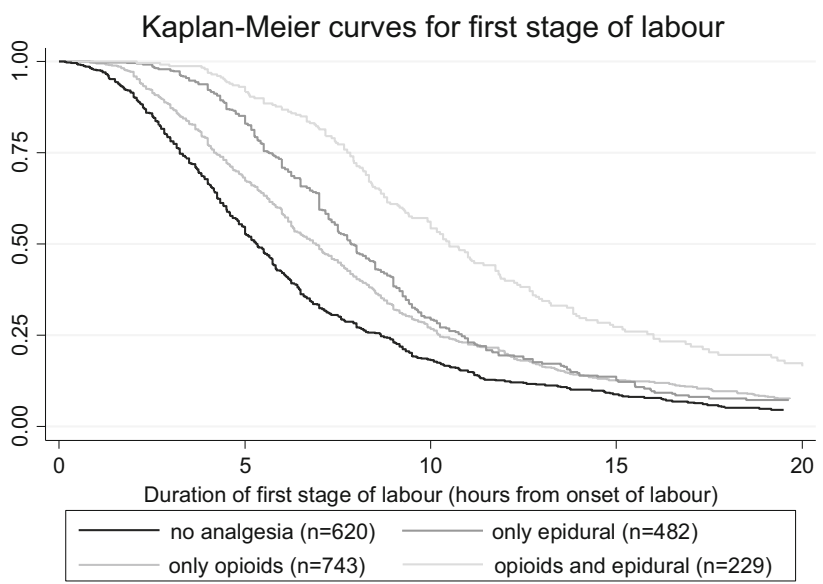

Fig. 1 Kaplan-Meier estimation for the duration of first stage of labour by study group $(n=2074$ nulliparae plus VBAC). This figure shows the Kaplan-Meier curves by study group for the duration of the first stage of labour. First stage was defined in hours from the onset of labour until full cervical dilatation was achieved. First-stage caesarean sections were treated as censored. Duration of the first stage was compared by log-rank test, $p<0.05$. Study group $1(n=620)$ had significantly the shortest first stage of labour $(p<0.001)$, and study group $4(n=229)$ had the longest duration compared to the other study groups $(p<0.001)$. The first stage for study group 2 $(n=743)$ was shorter compared to study group $3(n=482)$ $(p<0.010)$ and shorter compared to study group $4(p<0.001)$ 


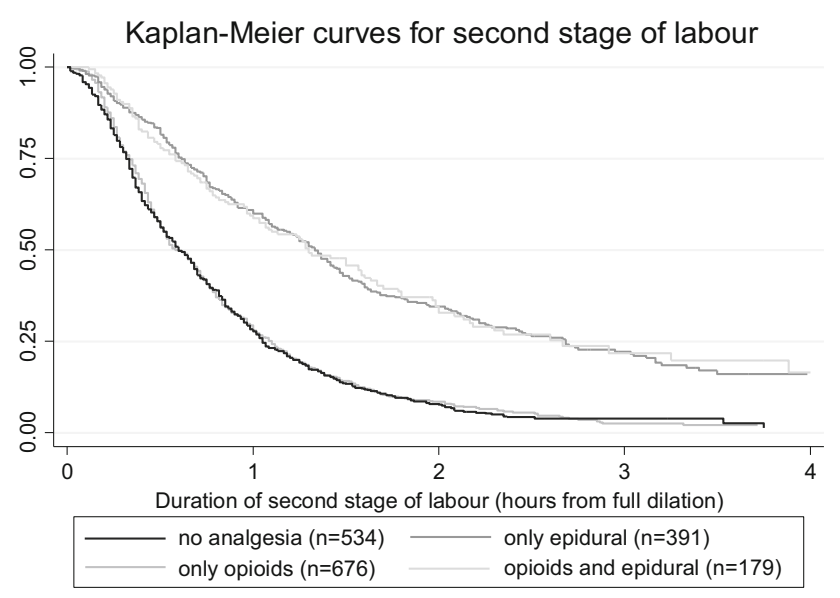

Fig. 2 Kaplan-Meier estimation for the duration of second stage of labour by study group ( $n=1780$ nulliparae). This figure shows the Kaplan-Meier curves by study group for the duration of the second stage of labour. Second stage was defined in hours from full cervical dilatation until birth. Operative births were treated as censored. Duration of the second stage was compared by the log-rank test, $p<0.05$. The log-rank tests showed that for the second stage of labour, study group $1(n=534)$ and study group $2(n=676)$ did not differ from each other $(p=0.673)$, but both were significantly shorter than the second stages of labour of study group $3(n=391)$ and study group $4(n=179)(1$ vs. $3 p<0.001 ; 1$ vs. $4 p<0.001 ; 2$ vs. 3 $p<0.001 ; 2$ vs. $4 p<0.001)$. The second stage of study group 3 and study group 4 did not differ from each other $(p=0.920)$

epidural (HR 0.686, $95 \%$ CI 0.598-0.788) and women with opioids (HR 0.867, $95 \%$ CI 0.769-0.976, $p=0.018$ ). Women with PROM, induction, and a cervical dilatation $\geq 3 \mathrm{~cm}$ at admission had a shorter first stage and a higher chance to reach full cervical dilatation $(p<0.001)$. No risks before onset of labour $(p=0.003)$ and oxytocin augmentation $(p<0.001)$ were associated with a prolonged first stage.

Compared with women without analgesia, the duration of the second stage was significantly prolonged for women with an epidural (HR 0.488, 95\% CI 0.418-0.570, $p<0.001)$ and women with both opioids and an epidural (HR 0.503, $95 \%$ CI 0.407-0.621, $p<0.001$; Table 3). No significant difference was found between the group without analgesia and the group with opioids $(p=0.917)$. Advanced maternal age, PROM, advanced cervical dilatation at admission, oxytocin, and increased fetal weight were associated with a prolonged second stage.

\section{Full cervical dilatation and mode of birth}

Women with opioids had an increased chance to reach full dilatation ( $p=0.006$; Table 4$)$, whereas women with a combination of opioids and epidural $(p<0.001)$ had a decreased chance to reach full cervical dilatation and, therefore, an increased risk of a first-stage caesarean section compared to women without analgesia. No significant difference was found between the group without analgesia and the group with epidural analgesia $(p=0.084)$. The factors vaginal birth after caesarean (VBAC) and induction decreased the chance of reaching full cervical dilatation.

Women with epidural analgesia and to higher extent women with opioid and epidural analgesia had a significantly decreased chance of a spontaneous birth compared with women without analgesia $(p<0.001$; Table 5). Opioid analgesia alone was not significantly associated with the mode of birth compared to no analgesia $(p=0.077)$. The factors advanced maternal age, VBAC, induction, and oxytocin augmentation decreased the chance of a spontaneous birth. Based on the odds ratio, it appeared that every additional hour of labour reduced the chance of spontaneous birth by $3.1 \%$. Women with $\geq 3 \mathrm{~cm}$ cervical dilatation at admission or women pregnant of a female neonate had an increased chance of a spontaneous birth.

\section{Discussion}

The outcomes of this study show that there is a significant difference in the duration of the first and second stage of labour and a chance to give birth spontaneously if analgesia with opioids, epidural, or a combination of both was administered. Nulliparous women without analgesia had the shortest labour duration and the highest chance of a spontaneous birth. When analgesia was administered, women with both opioid and epidural analgesia had the longest duration of both the first and second stage of labour; thereafter, the longest duration was found for women with only epidural analgesia. A significantly prolonged second stage of labour and a lower chance on a spontaneous birth were found for women with epidural analgesia with the lowest chance being for women with a combination of epidural and opioid analgesia.

\section{Strengths and limitations}

Due to the study, not being a prospective randomised controlled trial causality could not be established between methods of labour pain relief and duration of different labour stages. Despite this limitation, it is the first study that examined the combination of opioid and epidural analgesia during the process of labour in nulliparae. This study shows the differences between aspects of how long first and second stage of labour last and how many women are able to give birth spontaneously. For example, women with opioids had a prolonged first stage, but of this group, more women achieved full cervical dilatation. In contrast, 
Table 3 Cox regression: duration of first and second stage by study group $(n=2074)$

\begin{tabular}{|c|c|c|c|}
\hline Study group & Hazard ratio & $95 \% \mathrm{CI}$ & $p$ value \\
\hline \multicolumn{4}{|l|}{ First stage $^{\mathrm{a}}$} \\
\hline Maternal age ( $\geq 35$ years) & 0.964 & $0.839-1.108$ & 0.606 \\
\hline No risks before onset & 0.861 & $0.781-0.949$ & 0.003 \\
\hline PROM & 1.617 & $1.444-1.811$ & $<0.001$ \\
\hline Cervical dilatation at admission $(\geq 3 \mathrm{~cm})$ & 1.644 & $1.485-1.820$ & $<0.001$ \\
\hline Induction & 1.452 & $1.297-1.626$ & $<0.001$ \\
\hline Oxytocin augmentation & 0.639 & $0.578-0.707$ & $<0.001$ \\
\hline Fetal weight $(\geq 4000 \mathrm{~g})$ & 0.932 & $0.800-1.084$ & 0.361 \\
\hline Retrospective data & 0.945 & $0.851-1.049$ & 0.285 \\
\hline Study group 1: no analgesia & 1 & & \\
\hline Study group 2: only opioids & 0.867 & $0.769-0.976$ & 0.018 \\
\hline Study group 3: only epidural & 0.686 & $0.598-0.788$ & $<0.001$ \\
\hline Study group 4: opioids and epidural & 0.521 & $0.434-0.624$ & $<0.001$ \\
\hline \multicolumn{4}{|l|}{ Second stage ${ }^{\mathrm{b}}$} \\
\hline Maternal age ( $\geq 35$ years) & 0.767 & $0.656-0.897$ & 0.001 \\
\hline PROM & 0.867 & $0.768-0.979$ & 0.022 \\
\hline Cervical dilatation at admission $(\geq 3 \mathrm{~cm})$ & 0.816 & $0.733-0.909$ & $<0.001$ \\
\hline Oxytocin augmentation & 0.517 & $0.463-0.577$ & $<0.001$ \\
\hline Fetal weight $(\geq 4000 \mathrm{~g})$ & 0.688 & $0.579-0.818$ & $<0.001$ \\
\hline Retrospective data & 1.073 & $0.957-1.202$ & 0.228 \\
\hline Study group 1: no analgesia & 1 & & \\
\hline Study group 2: only opioids & 1.009 & $0.892-1.143$ & 0.884 \\
\hline Study group 3: only epidural & 0.488 & $0.418-0.570$ & $<0.001$ \\
\hline Study group 4: opioids and epidural & 0.503 & $0.407-0.621$ & $<0.001$ \\
\hline
\end{tabular}

Table 4 Logistic regression (backward elimination): association of factors and study groups with full cervical dilatation compared to those who experience an emergency caesarean $(n=2074)$

\begin{tabular}{lllr}
\hline Variable & OR & $95 \%$ CI & $p$ value \\
\hline Maternal age ( $\geq 35$ years) & 0.763 & $0.547-1.065$ & 0.112 \\
VBAC & 0.495 & $0.346-0.707$ & $<0.001$ \\
Induction & 0.489 & $0.377-0.634$ & $<0.001$ \\
Fetal weight $(\geq 4000 \mathrm{~g})$ & 0.920 & $0.622-1.360$ & 0.676 \\
Retrospective data & 1.116 & $0.843-1.479$ & 0.443 \\
Study group 1: no analgesia & 1 & & \\
Study group 2: only opioids & 1.625 & $1.153-2.292$ & 0.006 \\
Study group 3: only epidural & 0.747 & $0.537-1.040$ & 0.084 \\
Study group 4: opioids + epidural & 0.627 & $0.422-0.932$ & 0.021 \\
\hline
\end{tabular}

The group without analgesia was used as reference group

women who were induced had a shorter first stage, but fewer women achieved full cervical dilatation.

In addition given this study's detailed information, some predictors may differ in their meaning depending on whether the timing or the frequency aspect was asked.
Increased fetal weight was not relevant for the duration of first stage of labour, but for a longer duration of second stage of labour and if women had a spontaneous birth at all. A large sample of women could be included in this study, and because of the longitudinal design, the investigation was carried out within the dynamics belonging to labour.

There might be a difference in the documentation of factors in the retrospective sample compared to the prospective data setting. Therefore, this factor was always included in the multivariate models. The inclusion of induced labour might have increased the amount of intrapartum analgesia, because other studies have described a higher request for pharmacological pain relief associated with the induction of labour [11, 13, 28].

Analysis was performed without time-dependent covariate analysis which might have introduced time-dependent bias [29, 30]. This means that analgesia was considered as a time-fixed variable instead of time-depending covariate, which might have biased the hazard ratios downwards towards a lower risk [29]. For future research, it would be interesting to include data on the 
Table 5 Logistic regression (backward elimination): association of factors and study groups with spontaneous birth compared to those who experienced vaginal operative or caesarean births $(n=2074)$

\begin{tabular}{llrr}
\hline Variable & OR & $95 \%$ CI & $p$ value \\
\hline Maternal age ( $\geq 35$ years) & 0.650 & $0.494-0.854$ & 0.002 \\
VBAC & 0.644 & $0.467-0.887$ & 0.007 \\
Cervical dilatation at admission $(\geq 3 \mathrm{~cm})$ & 1.508 & $1.208-1.882$ & $<0.001$ \\
Induction & 0.628 & $0.503-0.784$ & $<0.001$ \\
Oxytocin augmentation & 0.724 & $0.578-0.906$ & 0.005 \\
Fetal weight $(\geq 4000$ g) & 0.746 & $0.545-1.020$ & 0.007 \\
Female sex & 1.262 & $1.028-1.549$ & 0.026 \\
Duration of total labour & 0.969 & $0.954-0.984$ & $<0.001$ \\
Retrospective data & 1.034 & $0.823-1.298$ & 0.775 \\
Study group 1: no analgesia & 1 & & \\
Study group 2: only opioids & 1.285 & $0.973-1.698$ & 0.077 \\
Study group 3: only epidural & 0.504 & $0.379-0.671$ & $<0.001$ \\
Study group 4: opioids + epidural & 0.469 & $0.328-0.670$ & $<0.001$ \\
\hline
\end{tabular}

The group without analgesia was used as reference group quality of pain measured with a score like VAS, to analyse if side effects were reported with different analgesic approaches, and to analyse neonatal and maternal outcomes.

\section{Combination of analgesia}

It was found that women who received both epidural and opioid analgesia received in most cases opioid analgesia first. The time interval between opioid and epidural analgesia of median $2.65 \mathrm{~h}$ is quite short with respect to the half-time period of the opioids; therefore, adverse effects like blood pressure disturbances need close meshed surveillance of the women. The cascade of analgesia could not be further analysed, as the group with first epidural analgesia was too small $(n=5)$. An additional pharmacological analgesia like Buscopan (C) was administered twice as much in the cases of opioid analgesia or a combination of opioid and epidural analgesia compared to women without analgesia or only epidural analgesia. These findings can be explained by the fact that epidural analgesia ensures more effective pain relief than opioid analgesia [1, 19]. The high rates of Buscopan (C)-use can be criticised, because there is an insufficient evidence to make any conclusions regarding the safety of this drug for mother and baby [31]. In addition, only low-quality evidence is available that states that antispasmodics reduce the duration of the first stage of labour and of total labour [31].

\section{Duration of first stage}

Nulliparous women with opioids as well as nulliparous women with epidural analgesia had a prolonged first stage of labour, which is in accordance with other observational studies [32, 33]. However, randomised trials found no prolonged first stage when epidural analgesia was administered [1, 19]. A prolonged first stage in women with epidural analgesia and to a higher extent in women with both types of analgesia can be interpreted as a complicated labour progress with more need for analgesia and care during labour [4, 10, 18]. This is supported by the findings of known predictors for the application of epidural analgesia, such as induction, PROM, and oxytocin augmentation [28, 34-36], which were found in this study to be associated with first-stage duration.

\section{Duration of second stage}

Nulliparous women with epidural analgesia or with administration of both opioids and epidural had a prolonged second stage of labour compared to nulliparous women without analgesia. Several other studies confirm the finding that epidural analgesia prolongs the second stage of labour [1, 19, 33, 37, 38]. Association between epidural analgesia or combined administration and a prolonged second stage is probably strengthened, because complicated and prolonged labour are risk factors for epidural analgesia or combined administration [4, 34, 39]. Opioid analgesia was found not to be associated with the duration of the second stage. This could be attributed to that fact that late application of opioid analgesia is commonly avoided to reduce the chance of a neonatal respiratory depression [1].

\section{Mode of birth}

Nulliparous women with epidural analgesia and nulliparous women with both types of analgesia had a decreased chance of having a spontaneous birth compared with nulliparous women without analgesia. These findings of a decreased chance of a spontaneous birth were in 
accordance with findings from a Cochrane systematic review [19] as well as with smaller observational studies $[28,32,33,40]$. In another analysis of the ProGeb-study by Gross et al. [41], an increased risk of caesarean sections was found for women with epidural analgesia increasing with later administration. Although, it is difficult to know if epidural analgesia or combined administration of analgesia reduce the chance of a spontaneous birth alone or which other factors interfere. Induction, early admission and PROM are known predictors for epidural analgesia, but these factors are also known to decrease the chance of a spontaneous birth [34, 42-44].

The current study showed an increased chance to reach full cervical dilatation when only opioids were administered. No other studies confirmed this finding and, therefore, more research on this subject is recommended.

\section{Implications of findings for midwifery practice}

The associations between the groups with pharmacological pain relief and the duration of first and second stage of labour as well as mode of birth allow specific future directions for counselling women. Results of the logistic regression give information on how many particular women had spontaneous births. Second, the results of the Cox regressions offer information on how long the particular interval lasts for various groups of women. These perspectives are relevant for midwifery practice and indicate that a preventive and alternative pain management regime which respects the stages of labour should be discussed with women. An option that should be considered by maternity care policy makers is to provide continuous support or midwife-led continuity of care from a small number of midwives. Women who receive this type of care have a shorter labour with a decreased risk on intrapartum interventions or intrapartum pain relief and have more chance on a spontaneous birth [11-13]. Furthermore, women report an increased sense of control and less dissatisfaction with their childbirth experience [7, 11-13]. Women's sense of control and positive childbirth experiences are important factors which decrease the risk of a post-natal depression [45, 46] with additional consequences as well, positive childbirth experiences are positively associated with pain experience in a following childbirth [5].

Midwives have an important role during labour, because they are in the position to support women in the labour process with non-pharmacological interventions and can facilitate the woman to feel in control and break the cycle of fear, tension, and pain [6, 12]. This care policy can reduce the demand for pain relief and can therefore decrease the chance of a prolonged labour and increase the chance of a spontaneous birth. This study provides new insights regarding opioid and epidural analgesia that inform midwives and other obstetric caregivers. These outcomes should be discussed with the women during pregnancy and in labour to make an informed choice on pain relief.

\section{Conclusion}

Opioid and epidural analgesia were both associated with a prolonged first stage of labour. In addition, epidural analgesia was associated with a prolonged second stage. Women without analgesia had the highest chance of a spontaneous birth. Opioid analgesia was not always adequate at relieving the pain, because epidural analgesia was administered some hours afterwards.

Every woman in labour has the right to get pharmacological pain relief. Although, before analgesia administration, the caregiver should discuss the adverse effects of analgesia with women and should consider other nonpharmacological interventions to avoid side effects of pharmacological analgesia, especially when they are combined in a short time interval. Further research is needed to examine if adverse effects of different types of analgesia and of other interventions during labour reinforce each other. More longitudinal research is needed to investigate whether nulliparous women with risk factors have a prolonged labour or not with inclusion of timevarying covariates.

Acknowledgments The study was funded by the German Research Council (DFG).

\section{Compliance with ethical standards}

Funding This study was funded by the German Research Council (DFG; Grant number GR 1917/4-1).

Conflict of interest All authors declare that they have no conflict of interest.

Ethical approval All procedures performed in studies involving human participants were in accordance with the ethical standards of the institutional and/or national research committee and with the 1964 Helsinki declaration and its later amendments or comparable ethical standards.

Informed consent Informed consent was obtained from all individual participants included in the study.

\section{References}

1. Jones L, Othman M, Dowswell T, Alfirevic Z, Gates S, Newburn M, Jordan S, Lavender T, Neilson JP (2012) Pain management for women in labour: an overview of systematic reviews. Cochrane Database Syst Rev 14(3):CD009234. doi:10.1002/ 14651858.CD009234.pub2 
2. Eley VA, Callaway L, van Zundert AA (2015) Developments in labour analgesia and their use in Australia. Anaesth Intensive Care 43:12-21

3. Simkin P, Bolding A (2004) Update on nonpharmacologic approaches to relieve labor pain and prevent suffering. J Midwifery Womens Health 49(6):489-504

4. Van der Gucht N, Lewis K (2015) Women's experiences of coping with pain during childbirth: a critical review of qualitative research. Midwifery 31(3):349-358. doi:10.1016/j.midw.2014. 12.005

5. Lowe NK (2002) The nature of labor pain. Am J Obstet Gynecol 186(5 Suppl Nature):S16-S24

6. Leap N, Anderson T (2004) The role of pain in normal birth and the empowerment of women. In: Downe S (ed) Normal childbirth: evidence and debate. Churchill Livingstone, Edinburgh, pp 25-39

7. Leap N, Sandall J, Buckland S, Huber U (2010) Journey to confidence: women's experiences of pain in labour and relational continuity of care. J Midwifery Womens Health 55(3):234-242

8. Gross MM, Hecker H, Keirse MJ (2005) An evaluation of pain and "fitness" during labor and its acceptability to women. Birth 32(2):122-128

9. van Cranenburgh B (2009) Pijn. Vanuit een neurowetenschappelijk perspectief. Reed Business, Amsterdam

10. Hodnett ED (2002) Pain and women's satisfaction with the experience of childbirth: a systematic review. Am J Obstet Gynecol 186(5 Suppl Nature):S160-S172

11. Hodnett ED, Gates S, Hofmeyr GJ, Sakala C (2013) Continuous support for women during childbirth. Cochrane Database Syst Rev 16(2):CD003766. doi:10.1002/14651858.CD003766.pub3

12. Hatem M, Sandall J, Devane D, Soltani H, Gates S (2008) Midwife-led versus other models of care for childbearing women. Cochrane Database Syst Rev 8(4):CD004667. doi:10.1002/ 14651858.CD004667.pub2

13. Sandall J, Soltani H, Gates S, Shennan A, Devane D (2016) Midwife-led continuity models versus other models of care for childbearing women. Cochrane Database Syst Rev 4:CD004667. doi:10.1002/14651858.CD004667.pub5

14. Lawrence A, Lewis L, Hofmeyr GJ, Dowswell T, Styles C (2009) Maternal positions and mobility during first stage labour. Cochrane Database Syst Rev 15(2):CD003934. doi:10.1002/ 14651858.CD003934.pub2

15. Kemp E, Kingswood CJ, Kibuka M, Thornton JG (2013) Position in the second stage of labour for women with epidural anaesthesia. Cochrane Database Syst Rev 31(1):CD008070. doi:10. 1002/14651858.CD008070.pub2

16. Smith CA, Levett KM, Collins CT, Crowther CA (2011) Relaxation techniques for pain management in labour. Cochrane Database Syst Rev 7(12):CD009514. doi:10.1002/14651858

17. Grant EN, Tao W, Craig M, McIntire D, Leveno K (2015) Neuraxial analgesia effects on labour progression: facts, fallacies, uncertainties and the future. BJOG 122(3):288-293. doi:10.1111/ 1471-0528.12966

18. Green JM, Baston HA (2003) Feeling in control during labour: concepts, correlates, and consequences. Birth 30(4):235-247

19. Anim-Somuah M, Smyth RM, Jones L (2011) Epidural versus non-epidural or no analgesia in labour. Cochrane Database Syst Rev 7(12):CD000331. doi:10.1002/14651858.CD000331.pub3

20. Ullman R, Smith LA, Burns E, Mori R, Dowswell T (2010) Parenteral opioids for maternal pain relief in labour. Cochrane Database Syst Rev 8(9):CD007396. doi:10.1002/14651858. CD007396.pub2

21. Petersen A, Ayerle GM, Frömke C, Hecker H, Gross MM, ProGebStudyTeam (2011) The timing of interventions during labour: descriptive results of a longitudinal study. Midwifery 27(6):267-273
22. Gross MM, Burian RA, Frömke C, Hecker H, Schippert C, Hillemanns P (2009) Onset of labour: women's experiences and midwives' assessments in relation to first stage duration. Arch Gynecol Obstet 280(6):899-905. doi:10.1007/s00404-009-0990-7

23. Petersen A, Potter U, Michelsen C, Gross MM (2013) The sequence of intrapartum interventions: a descriptive approach to the cascade of interventions. Arch Gynecol Obstet 288(2): 245-254

24. German Society of Obstetrics and Gynaecology (DGGG) (2010) Tocolytics to prevent preterm birth. AWMF 015/025. http://www. dggg.de/leitlinien/aktuelle-leitlinien/S. Accessed 20 Nov 2014

25. Nowotzek A, Hecker H, Hillemanns P, Gross MM (2007) Vergleich zwischen geburtshilflich-anästhesiologischen Klinikprofilen in Niedersachsen und anästhesiologischen Angaben in der ProGeb-Studie (Obstetrical-anaestheologic clinic profiles in Lower Saxony compared to anaesthesiologic data in the ProGeb study). Geburtsh Frauenheilkd 68:906

26. Bland JM, Altman DG (2004) The logrank test. BMJ 328:1073-1074

27. Hosmer DW, Lemeshow S (2000) Model-building strategies and methods for logistic regression, chapter 4. In: Hosmer DW, Lemeshow S (eds) Applied logistic regression, 2nd edn. Wiley, New York

28. Tracy SK, Sullivan E, Wang YA, Black D, Tracy M (2007) Birth outcomes associated with interventions in labour amongst low risk women: a population-based study. Women Birth 20(2):41-48

29. van Walraven C, Davis D, Forster AJ et al (2004) Time-dependent bias was common in survival analyses published in leading clinical journals. J Clin Epidemiol 57(7):672-682

30. Shintani AK, Girard TD, Eden SK, Arbogast PG, Moons KG, Ely EW (2009) Immortal time bias in critical care research: application of time-varying Cox regression for observational cohort studies. Crit Care Med 37(11):2939-2945

31. Rohwer AC, Khondowe O, Young T (2013) Antispasmodics for labour. Cochrane Database Syst Rev 5(6):CD009243. doi:10. 1002/14651858.CD009243.pub3

32. Bhattacharya S, Wang T, Knox F (2006) Analgesia for labour pain-analysis of the trends and associations in the Grampian region of Scotland between 1986 and 2001. BMC Pregnancy Childbirth 19(6): 14

33. Hasegawa J, Farina A, Turchi G, Hasegawa Y, Zanello M, Baroncini S (2013) Effects of epidural analgesia on labor length, instrumental delivery, and neonatal short-term outcome. J Anesth 27(1):43-47

34. Vahratian A, Zhang J, Troendle JF, Sciscione AC, Hoffman MK (2005) Labor progression and risk of cesarean delivery in electively induced nulliparas. Obstet Gynecol 105(4):698-704

35. Caughey AB, Sundaram V, Kaimal AJ, Cheng YW, Gienger A, Little SE, Lee JF, Wong L, Shaffer BL, Tran SH, Padula A, McDonald KM, Long EF, Owens DK, Bravata DM (2009) Maternal and neonatal outcomes of elective induction of labor. Evid Rep Technol Assess 176:1-257

36. Janssen PA, Weissinger S (2014) Women's perception of prehospital labour duration and obstetrical outcomes; a prospective cohort study. BMC Pregnancy Childbirth 14:182

37. Schiessl B, Janni W, Jundt K, Rammel G, Peschers U, Kainer F (2005) Obstetrical parameters influencing the duration of the second stage of labor. Eur J Obstet Gynecol Reprod Biol 118(1):17-20

38. Worstell T, Ahsan AD, Cahill AG, Caughey AB (2014) Length of the second stage of labor: what is the effect of an epidural? Obstet Gynecol 123(Suppl 1):84S

39. Bernitz S, Øian P, Rolland R, Sandvik L, Blix E (2014) Oxytocin and dystocia as risk factors for adverse birth outcomes: a cohort of low-risk nulliparous women. Midwifery 30(3):364-370. doi:10.1016/j.midw.2013.03.010 
40. Wassen MM, Hukkelhoven CW, Scheepers HC, Smits LJ, Nijhuis JG, Roumen FJ (2014) Epidural analgesia and operative delivery: a ten-year population-based cohort study in The Netherlands. Eur J Obstet Gynecol Reprod Biol 183:125-131

41. Gross M, Fromke C, Hecker H (2014) The timing of amniotomy, oxytocin and neuraxial analgesia and its association with labour duration and mode of birth. Arch Gynecol Obstet 289(1):41-48

42. Caughey AB, Nicholson JM, Cheng YW, Lyell DJ, Washington $\mathrm{AE}$ (2006) Induction of labor and cesarean delivery by gestational age. Am J Obstet Gynecol 195(3):700-705

43. Davey MA, McLachlan HL, Forster D, Flood M (2013) Influence of timing of admission in labour and management of labour on method of birth: results from a randomised controlled trial of caseload midwifery (COSMOS trial). Midwifery 29(12):12971302. doi:10.1016/j.midw.2013.05.014

44. Waldenström U, Hildingsson I, Rubertsson C, Rådestad I (2004) A negative birth experience: prevalence and risk factors in a national sample. Birth 31(1):17-27

45. Stewart DE, Robertson E, Dennis CL, Grace SL, Wallington T (2003) Postpartum depression: literature review of risk factors and interventions. University Health Network Women's Health Program, Published for Toronto public health

46. O'Hara MW, McCabe JE (2013) Postpartum depression: current status and future directions. Annu Rev Clin Psychol 9:379-407 